\title{
Hypericum extract was better than placebo and equivalent to imipramine for moderate depression
}

Philipp M, Kohnen R, Hiller KO. Hypericum extract versus imipramine or placebo in patients with moderate depression: randomised multicentre study of treatment for eight weeks. BMJ 1999 Dec 11;319:1534-9.

QUESTION: In patients with moderate depression, how do the effectiveness and safety of Hypericum extract (St John's wort) compare with those of imipramine and placebo?

Design

8 week randomised \{allocation concealed*\}†, blinded (clinicians and patients),* placebo controlled trial.

\section{Setting}

18 general practitioners' practices in Germany.

\section{Patients}

263 patients who were 18-65 years of age (mean age $47 \mathrm{y}, 75 \%$ women) and had a diagnosis of moderate depression; score of $\geq 18$ on the Hamilton Depression Rating Scale (HDRS); clinical global impression rating of moderate, marked, or severe; and depression lasting $\geq 4$ weeks and $\leqslant 2$ years. Exclusion criteria included bipolar disorders, alcohol or drug dependence, or suicidal risk. 230 patients $(87 \%)$ completed the study; $251(95 \%)$ were included in an intention to treat analysis.

\section{Intervention}

Patients were allocated to Hypericum extract (STEI 300, Steiner Arzneimittel, Berlin, Germany), $1050 \mathrm{mg}$ /day $(\mathrm{n}=106)$; imipramine, $50 \mathrm{mg} /$ day titrated to 100 $\mathrm{mg} /$ day by day $5(\mathrm{n}=110)$; or placebo $(\mathrm{n}=47)$.

\section{Main outcome measures}

The primary end point was change from baseline in HDRS score. Hypericum was compared with placebo at 6 weeks and with imipramine at 8 weeks.

Source of funding: Steiner Arzneimittel, Berlin, Germany.

For correspondence: Dr $K$ O Hiller, Steiner Arzneimittel, D-12207

Berlin, Germany. Fax

+49307125012.

Abstract also appears in Evidence-Based Mental Health

\section{Main results}

At 6 weeks, greater improvement from baseline occurred with Hypericum extract than with placebo (mean decrease in HDRS score of $13.4 v 10.3,95 \%$ CI for the 3.1 difference 1.5 to 5.4). At 8 weeks, Hypericum extract and imipramine had similar changes in score from baseline (mean decrease of $15.4 v 14.2$, CI for the 1.2 difference -0.6 to 2.6). More patients who received Hypericum extract had $\geq 50 \%$ improvement in HDRS scores than did patients who received placebo

Hypericum extract (HE) v placebo at 6 weeks and HE v imipramine (Imi) at 8 weeks for moderate depression $\$$

\begin{tabular}{|c|c|c|c|c|}
\hline Outcomes & Comparison & Event rates & $\mathrm{RBI}(95 \% \mathrm{Cl})$ & NNT (CI) \\
\hline \multirow{3}{*}{$\begin{array}{l}\geqslant 50 \% \text { improvement } \\
\text { in HDRS score }\end{array}$} & HE $v$ placebo & $67 \%$ v $48 \%$ & $40 \%(3.5$ to 101$)$ & 6 (3 to 50$)$ \\
\hline & HE $v$ Imi & $76 \%$ v $67 \%$ & $14 \%(-4.3$ to 37$)$ & Not significant \\
\hline & & & \multicolumn{2}{|l|}{$\operatorname{RRR}(\mathrm{Cl})$} \\
\hline Adverse effects & $\mathrm{HE} v \operatorname{Imi}$ & $22 \% v 46 \%$ & $53 \%$ (30 to 69$)$ & 4 (3 to 9$)$ \\
\hline
\end{tabular}

$\S$ HDRS = Hamilton Depression Rating Scale. Other abbreviations defined in glossary; RBI, RRR, NNT, and $\mathrm{Cl}$ calculated from data provided by the author. $\{\mathrm{p}=0.027\} \uparrow$, the proportions did not differ between Hypericum and imipramine $\{\mathrm{p}=0.14\} \$$ (table). Fewer patients in the Hypericum group than the imipramine group reported adverse effects $\{\mathrm{p}<0.001\} \ddagger$ (table).

\section{Conclusion}

In patients with moderate depression, Hypericum extract (St John's wort) was more effective than placebo and as effective and safe as imipramine.

*See glossary.

Information provided by author.

‡p Values calculated from data in article.

\section{COMMENTARY}

The trial by Philipp et al suggests that Hypericum extract may be considered as a treatment for moderate depression in primary care. To determine whether to prescribe Hypericum, some issues should be addressed.

The conclusion that Hypericum extract is safe in the long term is premature because of the limited duration of the study. Most patients are treated for many months. The fact that no data are available on concomitant pathology and drug treatments preclude statements about drug interactions. It has been shown that Hypericum induces the cytochrome $\mathrm{P} 450$, which might have serious clinical implications, for instance, in HIV infected patients on protease inhibitors. ${ }^{1}$ Interactions with such other drugs as cyclosporin, ${ }^{2}$ warfarin, theophylline, and some contraceptives have been reported. ${ }^{3}$ Furthermore, such common foods as grapefruit influence the same enzyme system. Future studies might consider using a crossover design, comparison with a selective serotonin reuptake inhibitor, or a higher dose of imipramine.

Hypericum perforatum is an herbal remedy that, although it is widely used and has promising results in this trial, is not yet completely understood. Because Hypericum products may vary considerably in composition, prescribers should be aware that study results may not be generalised to other extracts.

Etienne Vermeire, MD University of Antwerp Antwerp, Belgium

1 Piscitelli SC, Burstein AH, Chaitt D, et al. Indinavir concentrations and St John's wort. Lancet 2000;355:547-8.

2 Ruschitzka F, Meier PJ, Turina M, et al. Acute heart transplant rejection due to Saint John's wort. Lancet 2000;355:548-9.

3 Ernst E. Second thoughts about safety of St John's wort. Lancet 1999;354:2014-6. 